\title{
Comparison of Efficiency for Different Switching Tables in Six-Phase Induction Motor DTC Drive
}

\author{
Asghar Taheri ${ }^{\dagger}$, Abdolreza Rahmati*, and Shahriyar Kaboli** \\ $\dagger^{*}$ Dept. of Electrical and Electronics Eng., Iran University of Science \& Technology, Tehran, Iran \\ ${ }^{* *}$ Dept. of Electrical and Electronics Eng., Sharif University of Technology, Tehran, Iran
}

\begin{abstract}
In this paper, different switching tables proposed for the Direct Torque Controlled (DTC) of a six-phase induction machine are simulated and implemented. A six-phase induction motor has 64 space voltage vectors which result in increased complexity in the selecting of inverters switching. The unsuitable selection of a switching table leads to large harmonics especially at low speed and it also reduces drive efficiency. A six-phase induction machine has large zero sequence harmonic currents of the order $6 k \pm 1$. These harmonic currents are varied in various techniques. Decreasing this loss is essential in a six-phase induction machine. The main purpose of this paper is to improve the ST-DTC of six-phase induction machines to reduce the voltage and current harmonics and the torque pulsation. Selecting a suitable method for minimizing these harmonics is very important.
\end{abstract}

Key Words: Direct Torque Control, Efficiency Improvement, Six-Phase Induction Motor Drives

\section{INTRODUCTION}

Nowadays, a great deal of attention is being given to multiphase machines. Multi-phase machines with various structures are used in different applications. They are used in different applications including marine propulsion, railway traction, electric vehicles, and aerospace applications [1]-[3]. One of the major benefits of a six-phase induction machine is that it will continues working after cutting off one to three phases [1], [4]. A six-phase induction machine has two sets of three-phase windings, spatially phase shifted by 30 or 60 electrical degrees and with isolation or non-isolation of the neutrals [5]. 30 electrical degrees by isolation of the neutrals is selected in this paper. If the angle between two of the three phase windings is $\gamma=60^{\circ}$, the loss in the $6 k \pm 1,(k=1,3, \ldots)$ harmonics is zero and there is no need to improve this loss. Speed control of a six-phase induction machine can be accomplished by many approaches such as FOC [2], [6], [7] and DTC. Direct Torque Control of a six-phase induction machine has been reported in [3], [8]-[10]. Similar to a three-phase induction machine, there are two basic approaches for the DTC of a six-phase induction machine. The first technique is based on the hysteresis torque and flux control and followed by a voltage vector selecting table. In this approach the switching frequency is variable due to the hysteresis bands of the flux and torque controller. The second technique is based on a fixed switching frequency

Manuscript received Jun. 17, 2010; revised Oct. 31, 2011

Recommended for publication by Associate Editor Kyeong-Hwa Kim.

$\dagger$ Corresponding Author: taheri@znu.ac.ir

Tel: +98-241-515-2326, Fax: +98-241-515-9401, IUST

* Dept. of Electrical and Electronics Eng., Iran Univ. of Science \& Tech., Iran
[11]. The need for reduction of a low harmonic current due to the voltage vector plane is a major aspect which is not important in a three-phase induction machine [11]. A reduction of the loss in harmonics by the order $6 k \pm 1,(k=1,3, \ldots)$ in various space vector modulation techniques is reported in [12]-[15]. Designing an optimal switching table in six-phase direct torque control drives to reduce this loss is important. In [10] PWM-DTC of a symmetrical six-phase induction machine is presented. Accuracy in stator flux estimation is very important in the PWM-DTC of a six-phase induction motor. In [3] a split-phase induction machine is operated by two independent voltage source inverters. The proposed algorithms are complex and they are used in symmetrical sixphase induction machines.

In this paper the DTC of a six-phase induction machine is a fast and simple control strategy, which is tolerant to motor parameter variations. It provides direct control of the electromagnetic torque and stator flux by optimally selecting the inverter states in each sampling period. By comparing the various states in the inverter drive switching of a six-phase induction motor, a suitable state to reduce $6 k \pm 1,(k=1,3, \ldots)$ harmonics is obtained. In the previous papers published in this field, the authors did not use an optimal switching table. The unsuitable switching table selection used in [8] results in a large loss in the $\left(z_{1}-z_{2}\right)$ domain and a large torque ripple. Therefore, the authors of [8] say that ST-DTC is not useful or practical for a 6PIM with $\gamma=30^{\circ}$. The DTC of a five-phase induction motor is reported in [16-18]. In these papers, various techniques for the DTC of five-phase machines are described but the effects of different switching tables are not mentioned.

Different Switching Tables (ST) are proposed and compared 


$$
T 6=\left[\begin{array}{cccccc}
1 & \cos (\delta) & \cos \left(\frac{2 \pi}{3}\right) & \cos \left(\frac{2 \pi}{3}+\delta\right) & \cos \left(\frac{4 \pi}{3}\right) & \cos \left(\frac{4 \pi}{3}+\delta\right) \\
0 & \sin (\delta) & \sin \left(\frac{2 \pi}{3}\right) & \sin \left(\frac{2 \pi}{3}+\delta\right) & \sin \left(\frac{4 \pi}{3}\right) & \sin \left(\frac{4 \pi}{3}+\delta\right) \\
1 & \cos (\pi-\delta) & \cos \left(\frac{4 \pi}{3}\right) & \cos \left(\frac{\pi}{3}-\delta\right) & \cos \left(\frac{2 \pi}{3}\right) & \cos \left(\frac{5 \pi}{3}-\delta\right) \\
0 & \sin (\pi-\delta) & \sin \left(\frac{4 \pi}{3}\right) & \sin \left(\frac{\pi}{3}-\delta\right) & \sin \left(\frac{2 \pi}{3}\right) & \sin \left(\frac{5 \pi}{3}-\delta\right) \\
1 & 0 & 1 & 0 & 1 & 0 \\
0 & 1 & 0 & 1 & 0 & 1
\end{array}\right]
$$

in this paper to achieve a minimum loss in the $6 k \pm 1$ harmonic and a resultant reduction in the torque ripple. Improving the ST-DTC of a six-phase induction machine to reduce the harmonic of the fifth and seventh orders is given here. In the next section, the machine modeling is described. Then the DTC of a motor and the switching table used in this paper is presented. In section IV, the efficiency and losses in a sixphase induction machine are presented. The simulation results of various switching tables and loss in a 6PIM is presented in section V. The experimental results are shown in section VI and some conclusions are presented in section VII.

\section{Mathematical Model of SiX-Phase Induction MOTOR}

In the six-phase VSI shown in figure 1, the inverter has six legs and 64 voltage vectors. These voltage vectors are in 6 dimensional spaces and for the sake of simplicity they are mapped on three subspaces by the transformation matrix in (1). This simple and much discussed technique is the VSD method [5]. The fundamental supply harmonic that produces the electromechanical energy conversion is mapped on the $(\alpha-\beta)$ subspace. Also the harmonics of the order $(12 n \pm 1)$ are mapped on this subspace. The other subspace is $\left(z_{1}-z_{2}\right)$, and the harmonics of the order $6 k \pm 1,(k=1,3, \ldots)$ are mapped on it [5]. Because of the isolation of the neutrals of the two windings, the $\left(o_{1}-o_{2}\right)$ voltage vectors are all equal to zero [3], [8], [10].

$$
\left\{\begin{array}{l}
\bar{V}_{s}=R_{s} \bar{I}_{s}+\rho \bar{\Psi}_{s} \\
0=R_{r} \bar{I}_{r}+\rho \bar{\Psi}_{r}-j \omega_{r} \bar{\Psi}_{r} .
\end{array}\right.
$$

The flux equations produced in the $(\alpha-\beta)$ subspace are as:

$$
\left[\begin{array}{l}
\bar{\Psi}_{s} \\
\bar{\Psi}_{r}
\end{array}\right]=\left[\begin{array}{ll}
L_{S} & M \\
M & L_{r}
\end{array}\right]\left[\begin{array}{c}
\bar{I}_{S} \\
\bar{I}_{r}
\end{array}\right]
$$

where:

$$
L_{s}=L_{l s}+M, L_{r}=L_{l r}+M, M=3 L_{m s}
$$

The electromagnetic torque is reduced as:

$$
T_{e}=\frac{3 P}{2} I_{m}\left(\bar{\Psi}_{s} \cdot \bar{I}_{s}^{*}\right) .
$$

The six-phase induction machine in the $\left(z_{1}-z_{2}\right)$ subspace is modeled as [5]:

$$
\left[\begin{array}{c}
v_{s z 1} \\
v_{s z 2}
\end{array}\right]=\left[\begin{array}{cc}
R_{s}+\rho L_{l s} & 0 \\
0 & R_{s}+\rho L_{l s}
\end{array}\right]\left[\begin{array}{c}
i_{s z 1} \\
i_{s z 2}
\end{array}\right] .
$$

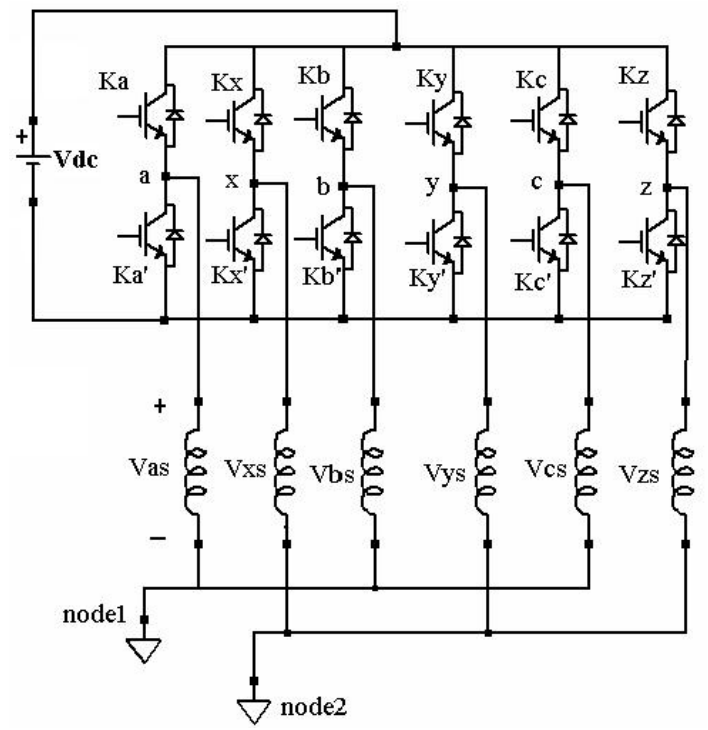

Fig. 1. Diagram of six-phase induction motor and inverter.

\section{DTC Method And Selecting Various Switching TABLES}

In the DTC technique the motor flux and the torque can be controlled without accurately determining the position of the rotor flux. For this purpose, finding the flux sector is enough. A fast decoupled control of the stator flux and the electromagnetic torque is the main object of the DTC technique. The inverter voltage vector is selected by hysteresis comparators of the flux and the torque and a switching logic table, as shown in fig 2. In a multi-phase induction machine with more space voltage vectors, there is more flexibility in selecting the inverter switching. Unsuitable selection of a switching table leads to large $6 k \pm 1,(k=1,3, \ldots)$ harmonics especially at low speeds and it results in a reduction of the drive efficiency.

To reduce these harmonics in the DTC of a six-phase induction machine, K. Hatua, et al. [3] individual the flux control method. In this technique, two different two-level flux hysteresis controllers are used separately for two stator fluxes $\left(\bar{\Psi}_{s 1}, \bar{\Psi}_{s 2}\right)$. In [10] the switching table DTC of a sixphase induction machine is a topic requiring further research. Because of the small stator impedance of the $\left(z_{1}-z_{2}\right)$ domain, the voltage harmonics of the order $6 k \pm 1,(k=1,3, \ldots)$ generate large stator current harmonics. In the previous papers published in this field, the authors did not use an optimal switching table. The unsuitable switching table selection used in [8] results in a large loss in the $\left(z_{1}-z_{2}\right)$ domain and a large torque ripple.

The selection of vectors in different solutions is carried 


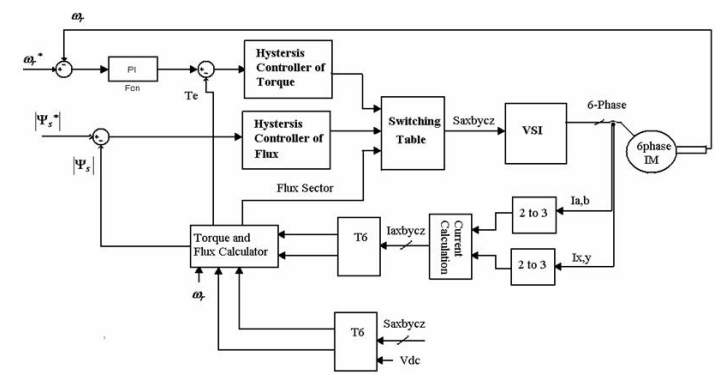

Fig. 2. Block diagram of DTC control of 6PIM.

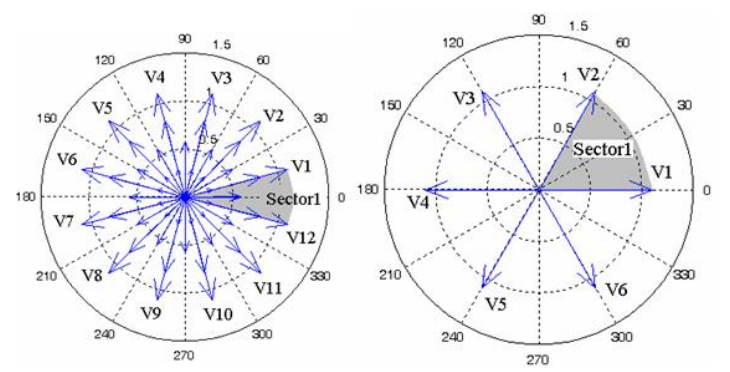

Fig. 3. Voltage vectors in the $(\alpha-\beta)$ subspace according to maximum amplitude, (a) $\gamma=30^{\circ}$, (b) $\gamma=60^{\circ}$.

out on the basis of the errors in the torque and in the stator flux, as shown in table 3 . This is assuming that the stator flux space vector in the $(\alpha-\beta)$ subspace is located in sector $\mathrm{k}(\mathrm{k}=1, \ldots$, and12). Selecting the voltage space vectors $v_{k}, v_{k+1}, v_{k-2}$ increases the flux magnitude while selecting $v_{k+4}, v_{k+6}, v_{k-5}$ decreases it. The zero voltage space vectors do not affect the stator flux. These voltages are selected from table 2 in order to minimize the switching loss. From (2), the stator flux can be calculated as:

$$
\begin{aligned}
& \psi_{s \alpha}=\int\left(V_{s \alpha}-R_{s} i_{s \alpha}\right) d t \\
& \psi_{s \beta}=\int\left(V_{s \beta}-R_{s} i_{s \beta}\right) d t .
\end{aligned}
$$

If the switching numbers are selected from table 2, they have minimum amplitude in the $\left(z_{1}-z_{2}\right)$ subspace. According to the supposed DTC method in fig 2, the switching table rules must be selected to decrease the flux and torque errors. The switching table must be selected in a manner which decreases the power loss in the $\left(z_{1}-z_{2}\right)$ subspace, thus increasing the efficiency of the motor. A 6PIM with direct torque control (DTC) and speed control are shown in Fig 2. The DTC rule is from table III.

\section{EFFiciency AND Losses IN A SIX-PHASE INDUCTION MACHINE}

To derive the expression of the efficiency, the input and output power must be calculated. For calculating the input power, the motor losses are calculated.

$$
P_{\text {in }}=P_{\text {out }}-P_{\text {loss }}
$$

Motor losses consist of electrical and mechanical losses. If the torque and the speed remain fixed, the output power is constant. A simple modeling of the input and output power is used for simplicity of the calculation efficiency.

$$
P_{\text {out }}=T * \omega \text {. }
$$

The losses of a six-phase induction machine consist of stator and rotor copper losses $\left(P_{c u}\right)$, copper loss in the $\left(z_{1}-z_{2}\right)$ subspace $\left(P_{z}\right)$, and core loss $\left(P_{c}\right)$. Other losses can be ignored to simplify the calculation of losses. The core losses consist of hysteresis and eddy current losses. These losses can be expressed as:

$$
P_{c}=P_{\text {hyst }}+P_{\text {eddy }} .
$$

The copper loss in the $\left(z_{1}-z_{2}\right)$ subspace can be expressed by:

$$
P_{z}=\frac{1}{2} R_{s}\left(i_{z 1}^{2}+i_{z 2}^{2}\right) \text {. }
$$

To simplify the computation of the input power, (13) can be used. As given in this equation, there is no need to calculate $P_{\text {loss }}$. The total input power to a six-phase induction motor can be calculated using only the DC voltage and current.

$$
P_{i n \_d c}=V_{d c} I_{d c} .
$$

The efficiency is calculated by the following formula:

$$
\eta=\frac{P_{\text {out }}}{P_{\text {in_dc }} \text {. }} \text {. }
$$

\section{Simulation Results}

In order to compare the effectiveness of various switching tables, a computer simulation model is developed using Matlab. The simulation results for five different proposed methods for switching tables are shown in Figure 4 and Figure 5. In figure 4, the simulation results for various parameters in high speed and changed load are shown. The motor speed is fixed in $100 \mathrm{rad} / \mathrm{s}$ and the motor load is varied. The motor load is $0.2 \mathrm{~N} . \mathrm{m}$ at startup and varied to $3.5 \mathrm{~N} . \mathrm{m}$ at 1.2 seconds. The motor load is varied to $1 \mathrm{~N} . \mathrm{m}$ at 4 seconds. In this figure, the output of the change in the electromagnetic torque, the loss in the $\left(z_{1}-z_{2}\right)$ domain, and the efficiency are presented. According to the simulation results, if the motor speed is high, solution A has the least torque ripple at low load $(0.2 \mathrm{~N} . \mathrm{m}$ and 1 N.m). At high speed and high load, solution B has as small a torque ripple as solution A. At high speed and low load conditions, solution $\mathrm{B}$ has a large torque ripple. The torque ripple in other techniques is large. Solution $\mathrm{E}$ has the largest torque ripple at various loads. The power loss in the $\left(z_{1}-z_{2}\right)$ domain in solutions A and B are less than the others.

In low and high loads, solutions $\mathrm{E}$ and $\mathrm{C}$ have the greatest losses in the $\left(z_{1}-z_{2}\right)$ domain. Solution D has less loss than solutions $\mathrm{C}$ and $\mathrm{E}$ and greater loss than solutions $\mathrm{A}$ and $\mathrm{B}$. Solutions $\mathrm{C}$ and $\mathrm{E}$ have the lowest efficiency at high speed.

Simulation results at low speed and varied loads are shown in figure 5. The motor speed is fixed at $20 \mathrm{rad} / \mathrm{sec}$ and the motor load is varied. The motor load is $0.2 \mathrm{~N} . \mathrm{m}$ at startup and varied to 3.5 N.m at 1.2 seconds. The motor load is then varied to 1 N.m at 4 seconds. In this figure, the output of the change in speed, the loss in the $\left(z_{1}-z_{2}\right)$ domain, and the efficiency are presented. According to the simulation results, if motor speed is low, solution $\mathrm{A}$ has the least torque ripple at low load $(0.2$ N.m and 1 N.m). When solution A is used, the torque ripple at low load and low speed is greater than the torque at low load and high speed conditions. However, at high 

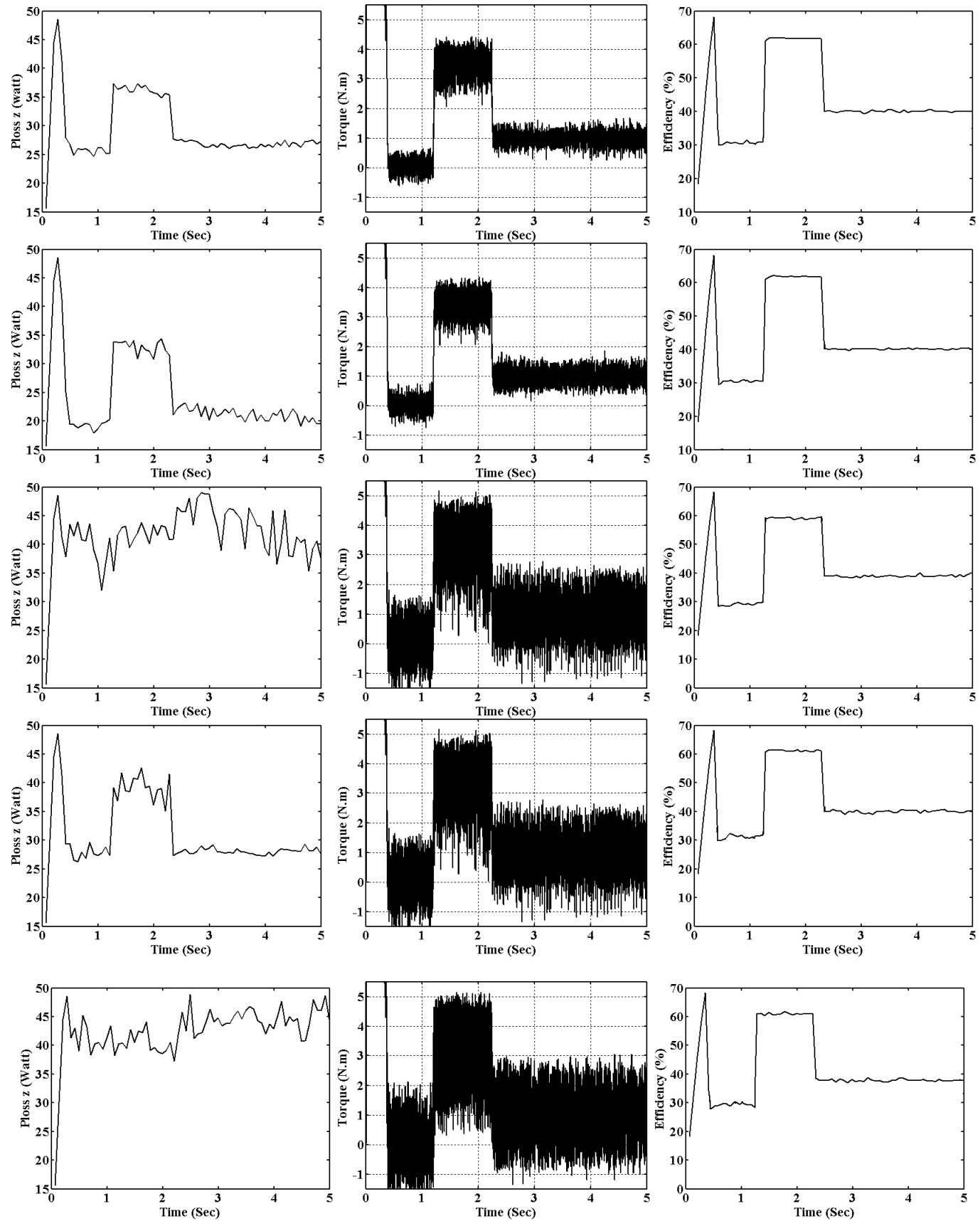

(a)

(b)

(c)

Fig. 4. Simulation results of various ST-DTC of 6-phase induction motor in high speed. (a) Power loss in $\left(z_{1}-z_{2}\right)$ domain. (b) motor torque. (c) Efficiency. From top to bottom solution A, solution B, solution C, solution D, and solution E.

TABLE I

VOLTAGE VECTORS

\begin{tabular}{|c|c|c|c|c|c|c|c|c|c|c|c|c|}
\hline V0 & V1 & V2 & V3 & V4 & V5 & V6 & V7 & V8 & V9 & V10 & V11 & V12 \\
\hline 0 & 48 & 56 & 60 & 28 & 12 & 14 & 15 & 7 & 3 & 35 & 51 & 49 \\
\hline
\end{tabular}

TABLE II

SWITCHING SOLUTIONS

\begin{tabular}{|c|c|c|c|c|c|c|c|}
\hline$\Delta \mathrm{T}$ & $\Delta \Psi$ & Solution A & Solution B & Solution C & Solution D & Solution E & Solution F \\
\hline \multirow{2}{*}{1} & 1 & $U_{k+1}$ & $U_{k+1}$ & $U_{k+1}$ & $U_{k+1}$ & $U_{k+1}$ & $U_{k+2}$ \\
\cline { 2 - 8 } & 0 & $U_{k+4}$ & $U_{k+4}$ & $U_{k+4}$ & $U_{k+4}$ & $U_{k+1}$ & $U_{k+3}$ \\
\hline \multirow{2}{*}{0} & 1 & $U_{0}$ & $U_{0}$ & $U_{0}$ & $U_{0}$ & $U_{0}$ & $U_{0}$ \\
\cline { 2 - 8 } & 0 & $U_{0}$ & $U_{0}$ & $U_{0}$ & $U_{0}$ & $U_{0}$ & $U_{0}$ \\
\hline \multirow{2}{*}{-1} & 1 & $U_{0}$ & $U_{k}$ & $U_{k}$ & $U_{k-2}$ & $U_{k-1}$ & $U_{k-3}$ \\
\cline { 2 - 8 } & 0 & $U_{0}$ & $U_{0}$ & $U_{k+6}$ & $U_{k-5}$ & $U_{k-4}$ & $U_{k-4}$ \\
\hline
\end{tabular}



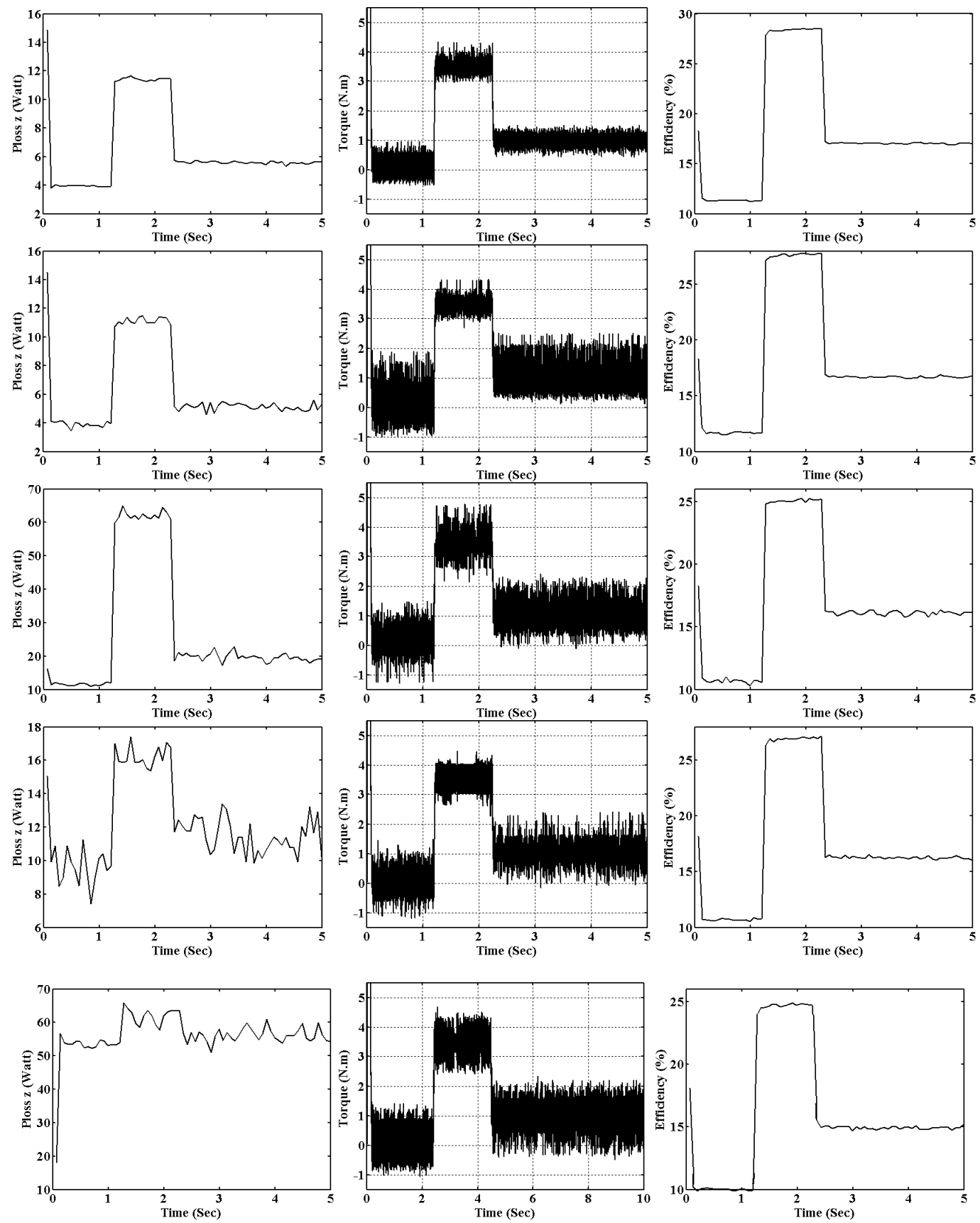

(a)

(b)

(c)

Fig. 5. Simulation results of various ST-DTC of six-phase induction motor in low speed. (a) Mean of power loss in $\left(z_{1}-z_{2}\right)$ domain,(b) motor torque, and (c) Efficiency. From top to bottom solution A, solution B, solution C, solution D, and solution E.

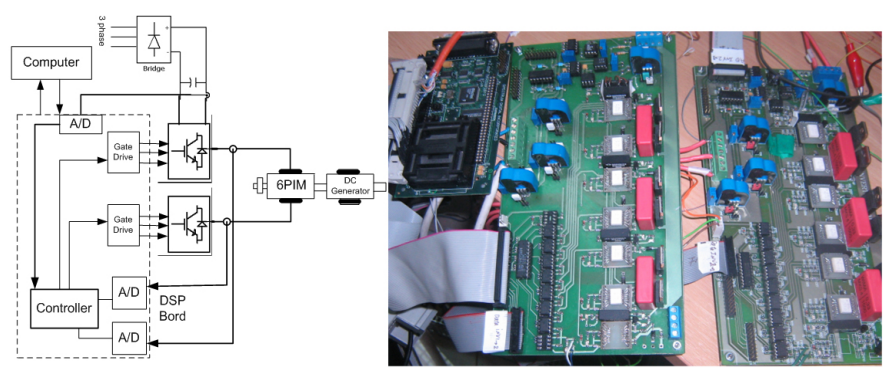

Fig. 6. Experimental setup. 

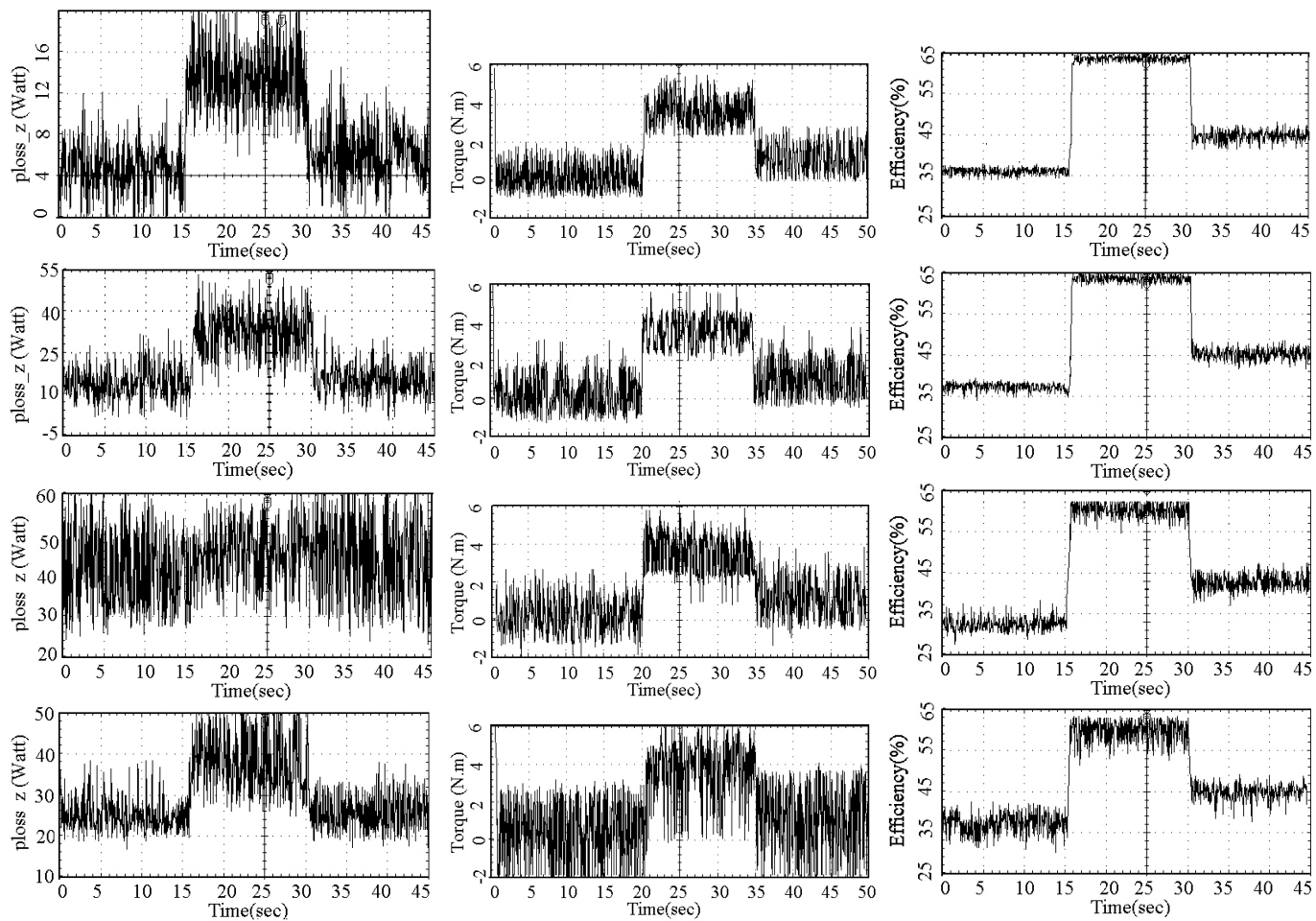

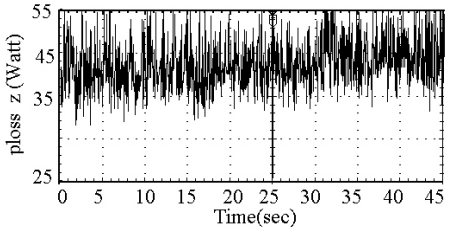

(a)

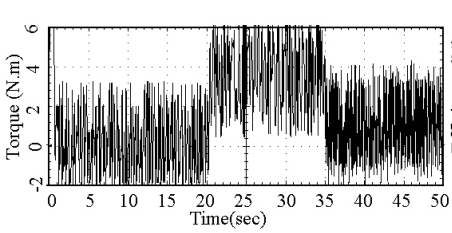

(b)

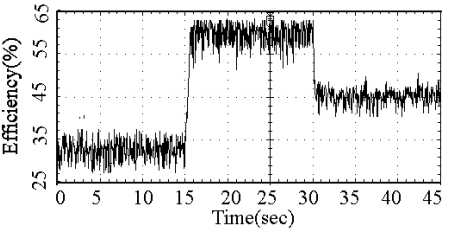

(c)

Fig. 7. Experimental results of various ST-DTC of six-phase induction motor in high speed. (a) Power loss in $\left(z_{1}-z_{2}\right)$ domain, (b) motor torque, and (c) Efficiency. From top to bottom solution A, solution B, solution C, solution D, and solution E.

TABLE III

SWITCHING TABLE IN SOLUTION D

\begin{tabular}{|c|c|c|c|c|c|c|c|c|c|c|c|c|c|}
\hline & & \multicolumn{12}{|c|}{ Sector number } \\
\hline$\Delta \mathrm{T}$ & $\Delta \Psi$ & 1 & 2 & 3 & 4 & 5 & 6 & 7 & 8 & 9 & 10 & 11 & 12 \\
\hline \multirow{2}{*}{1} & 1 & 2 & 3 & 4 & 5 & 6 & 7 & 8 & 9 & 10 & 11 & 12 & 1 \\
\hline & 0 & 5 & 6 & 7 & 8 & 9 & 10 & 11 & 12 & 1 & 2 & 3 & 4 \\
\hline \multirow{2}{*}{0} & 1 & 0 & 7 & 63 & 54 & 0 & 7 & 63 & 54 & 0 & 7 & 63 & 54 \\
\hline & 0 & 7 & 63 & 54 & 0 & 7 & 63 & 54 & 0 & 7 & 63 & 54 & 0 \\
\hline \multirow{2}{*}{-1} & 1 & 11 & 12 & 1 & 2 & 3 & 4 & 5 & 6 & 7 & 8 & 9 & 10 \\
\hline & 0 & 8 & 9 & 10 & 11 & 12 & 1 & 2 & 3 & 4 & 5 & 6 & 7 \\
\hline
\end{tabular}

load the torque ripples are almost similar. At low speed and high load, solution B has as small a torque ripple as solution A. In solution B, the torque ripple at low load is greater than at high speed, but the torque ripple at high load is less than at high speed. The torque ripples in solutions $\mathrm{C}, \mathrm{D}$, and $\mathrm{E}$ are large. Solution $\mathrm{E}$ and $\mathrm{C}$ have largest torque ripple at various loads. The torque ripples in solutions $\mathrm{C}, \mathrm{D}$, and $\mathrm{E}$ at low load are less than at high speed. The power losses in the $\left(z_{1}-z_{2}\right)$ domain in solutions $\mathrm{A}$ and $\mathrm{B}$ are better than in the others. At low and high loads, solution $\mathrm{E}$ has the greatest loss in the $\left(z_{1}-z_{2}\right)$ domain. Solution $\mathrm{C}$ has a small loss at low load, but the loss at high load is large. Solution D has a fast torque response to load torque variations.

\section{EXPERIMENTAL RESUlts}

The proposed techniques for comparing the loss in the $\left(z_{1}-z_{2}\right)$ domain and the efficiency have been developed and tested in an experimental set up. The system described in Fig.2 has been built. A six-phase induction motor was produced with a three-phase induction motor by rewinding the stator. This motor was wound for $\gamma=30^{\circ}$ to obtain a six-phase induction motor for experimental tests. The 6PIM was coupled to a DC machine that operates as a generator. Two three-phase inverters were designed and used to drive the motor. Various switching tables for the DTC of a six-phase induction motor are implemented on a dskf2812 board. The flux reference in the experiment remains constant. Experimental results for the various techniques are shown in figure 7 and 8 . The motor 

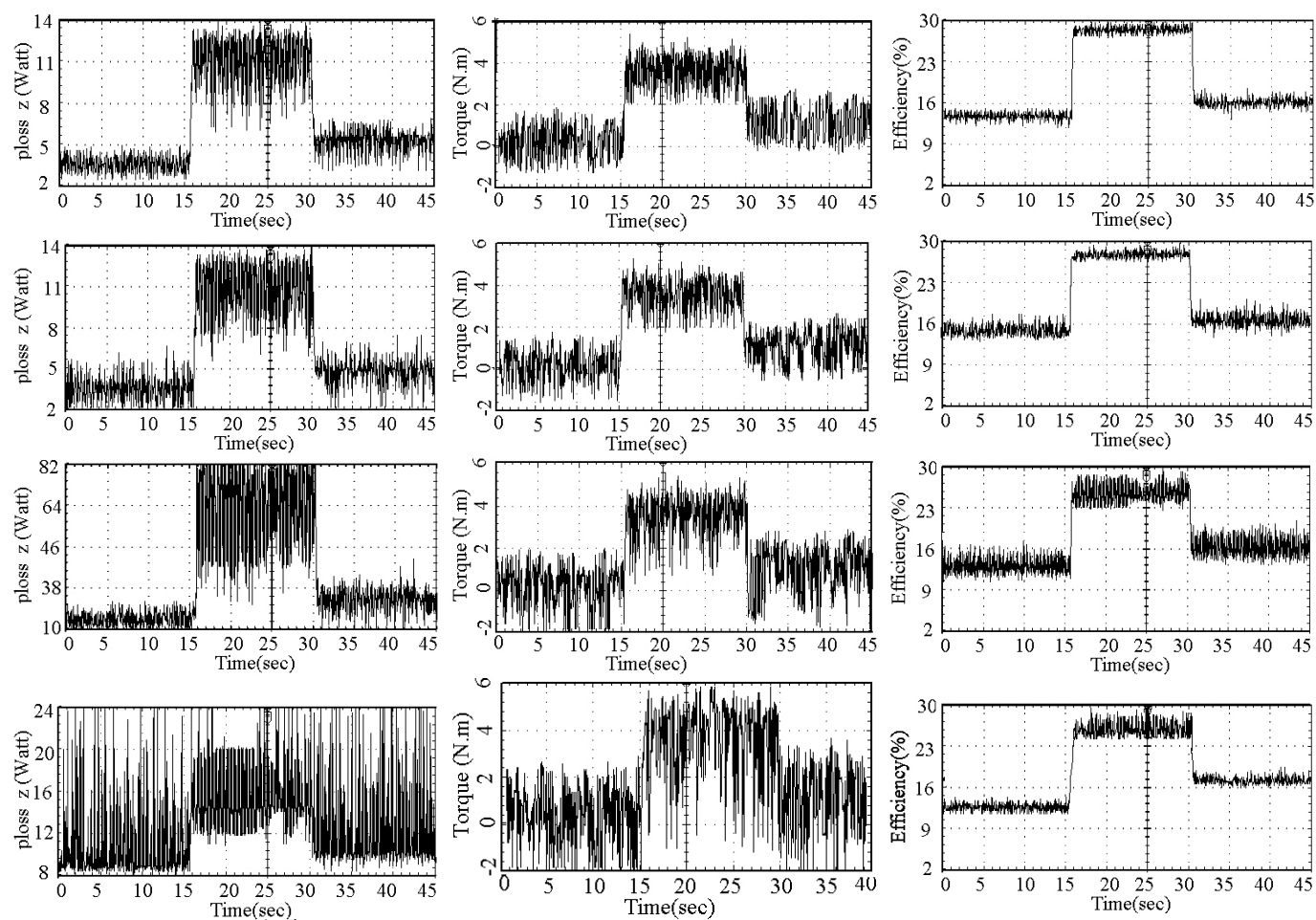

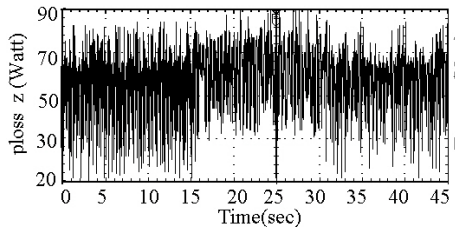

(a)

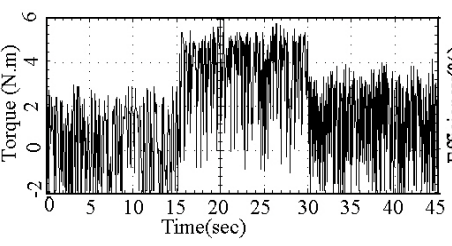

(b)

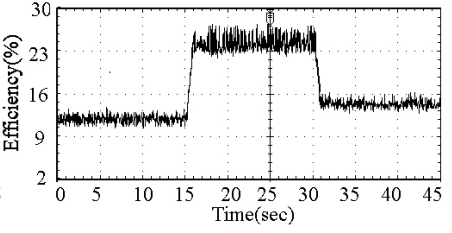

(c)

Fig. 8. Experimental results of various ST-DTC of six-phase induction motor in low speed. (a) Power loss in $\left(z_{1}-z_{2}\right)$ domain, (b) motor torque, and (c) Efficiency. From top to bottom solution A, solution B, solution C, solution D, and solution E.

speed reference is $100 \mathrm{rad} / \mathrm{s}$ at high load and $20 \mathrm{rad} / \mathrm{s}$ at low load. The load torque is $0.2 \mathrm{~N} . \mathrm{m}$ at startup and it is changed to 3.5 N.m after 15 seconds and to 1 N.m after 30 seconds. The motor speed reference is $100 \mathrm{rad} / \mathrm{s}$ at high load and 20 $\mathrm{rad} / \mathrm{s}$ at low load. The simulations and experimental results are almost the same. As can be seen from the experimental results in figures 7 and 8 , solutions $\mathrm{A}$ and $\mathrm{B}$ have minimum losses in the $\left(z_{1}-z_{2}\right)$ domain and the efficiency of these techniques is maximized.

Also the torque ripple in solution A is less than it is with the other solutions. However, the speed responses in solutions $\mathrm{A}$ and $\mathrm{B}$ are slower. The torque ripple in solutions A and B at high speed is less it is with the other solutions. The power loss in the $\left(z_{1}-z_{2}\right)$ domain is presented without averaging thus there are some variations with respect to the simulation results. The torque ripple at low speed and high speed with the various solutions are almost similar.

\section{CONCLUSION}

In this paper, after a brief review of six-phase induction motor structure modeling, different strategies in the DTC of that machine are compared. The different strategies have varied responses and efficiencies. Solutions A and B have larger efficiencies and minimum losses in the $\left(z_{1}-z_{2}\right)$ domain. Solution $\mathrm{A}$ has the least torque ripple at high speed and load variations. Solution B has as small a torque ripple as solution A at high speed and high load. Solution B is not useful at low load and high speed because of its large torque ripple. Solution $\mathrm{E}$ has the largest torque ripple in various loads. Also this solution has a large power loss in the $\left(z_{1}-z_{2}\right)$ domain. In low and high loads, solutions $\mathrm{E}$ and $\mathrm{C}$ have the greatest losses in the $\left(z_{1}-z_{2}\right)$ domain. Solution $\mathrm{D}$ has less loss than solutions $\mathrm{C}$ and $\mathrm{E}$ and greater loss than solution $\mathrm{A}$ and $\mathrm{B}$.

However, it has a fast torque response. Solutions $\mathrm{C}$ and $\mathrm{E}$ have the lowest efficiencies at high speed. If the motor load variations are low or the torque response is not very important, solution A is the best choice. Solution D is the best choice if the motor load is varied a great deal or the torque response time is important but the torque ripple is great.

\section{REFERENCES}

[1] R. Kianinezhad, B. N. Mobarakeh, L. Baghli, F. Betin, and G. A Capolino, "Modeling and control of six-phase symmetrical induction machine under fault condition due to open phases," IEEE Trans. Ind. Electron., Vol. 55, No. 5, pp. 1966-1977, May 2008.

[2] R. Bojoi, M. Lazzari, F. Profumo, and A. Tenconi, "Digital field-oriented control for dual three-phase induction motor drives," IEEE Trans. Ind. App., Vol. 39, No. 3, pp. 1243-1254, May/ Jun. 2003. 
[3] K. Hatua and V. T. Ranganathan, "Direct torque control schemes for split-phase induction machine," IEEE Trans. Ind. Appl., Vol. 41, No. 5, pp. 1243-1254, Sep./Oct. 2005.

[4] M. A. Fnaiech, F. Betin, G. A. Capolino, and F. Fnaiech, "Fuzzy logic and sliding-mode controls applied to six-phase induction machine with open phase," IEEE Trans. Ind. Electron., Vol. 57, No. 1, pp. 354-364, Jan. 2010.

[5] Y. Zhao and A. Lipo, "Space vector pwm control of dual three-phase induction machine using vector space decomposition," IEEE Trans. Ind Appl., Vol. 31, No. 5, pp 1100-1109, Sep./Oct. 1995.

[6] R. Bojoi, F. Farina, A. Tenconi, F. Profumi, and E. Levi, "Dual threephase induction motor drive with digital current control in the stationary reference frame," IET Jnl. Pow Eng, Vol 20, No.3, pp 40-43, Jun./Jul. 2006.

[7] G. Singh, K. Nam, and S. Lim, "A simple indirect field-oriented control scheme for multiphase induction machine," IEEE Trans. Ind. Electron., Vol. 52, No.4, Aug. 2005.

[8] R. Kianinezhad, B. Nahid, F. Betin, and G. A. Capolino, "A novel Direct Torque Control method for dual three phase induction motors," IEEE Conf. Ind. Tech. pp.939-943, Dec. 2006.

[9] K. Marouanil, F. Khouchal, A. Khelouil, L. Baghli, and D. Hadiouche, "Study and simulation of direct torque control of double-star induction motor drive," in Proc EPE-PEMC, pp 1233-1238, 2006.

[10] R. Bojoi, F. Farina, G. Griva, F. Profumo, and A. Tenconi, "Direct torque control for dual three- phase induction motor drives," IEEE Trans. Ind. Appl., Vol. 41, No. 6, pp. 1627-1636, Nov. 2005.

[11] E. Levi, R. Bojoi, F. Profumo, H. A. Toliyat, and S. Williamson, "Multiphase induction motor drives a technology status review," IET Electr. Power Appl., pp. 489-516, 2007.

[12] D. Hadiouche, H. Razik, and A. Rezzoug, "On the modeling and design of dual-stator windings to minimize circulating harmonic currents for VSI fed AC machines," IEEE Trans. Ind App, Vol. 40, No. 2, pp 506515, Mar./Apr. 2004.

[13] D. Yazdani, S. Khajehoddin, A. Bakhshai, and G. Joos, "Full utilization of the inverter in split-phase drives by means of a dual three-phase space vector classification algorithm," IEEE Trans. Ind. Electron., Vol. 56, No. 1, pp. 120-129, Jan. 2009.

[14] D. Hadiouche, L. Baghli, and A. Rezzoug, "Space vector pwm techniques for dual three-phase ac machine analysis, performance evaluation and dsp implementation," 38th IAS Annual Meeting, Vol. 1, No. 2, pp 648-655, Oct. 2003.

[15] K. Marouani, L. Baghli, D. Hadiouche, A. Kheloui, and A. Rezzoug, "A new pwm strategy based on a 24-sector vector space decomposition for a six-phase vsi-fed dual stator induction motor," IEEE Trans. Ind .Electron., Vol. 55, No. 5, pp 1910-1920, May 2008.

[16] H. Xu, H. A. Toliyat, and L. J. Petersen, "Five-phase induction motor drives with DSP-based control system," IEEE Trans. Power Electron., Vol. 17, No. 4, pp. 524-533, Jul. 2002.
[17] L. Zheng, J. E. Fletcher, B. W. Williams, and X. He, "A novel direct torque control scheme for a sensorless five-phase induction motor drive," IEEE Trans. Ind Electron., Vol. 58, No. 2, pp. 503-513. Feb. 2011.

[18] X. Kestelyn, E. Semail, and D. Loriol, "Direct torque control of a multiphase permanent magnet synchronous motor drive: application to a fivephase one," in Proc. IEMDC, pp. 137-143, 2005.

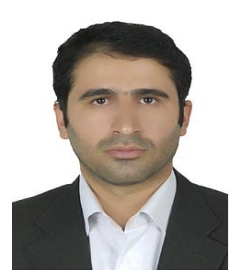

Asghar Taheri was born in Zanjan, Iran, in 1977. He received his B.S., M.S., and Ph.D. all in Electronics Engineering from the Amirkabir University of Technology and the Iran University of Science and Technology, Tehran, Iran, in 1999, 2001, and 2011, respectively. He has been a member of the faculty at the University of Zanjan since 2010 where he is currently an Assistant Professor. His current research interests include DSP and FPGA based system designs, motor drives and control, and multi phase machine drives and control.

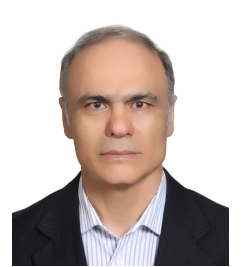

Abdolreza Rahmati was born in Abadeh, Iran. He received his B.S. in Electronics Engineering from the Iran University of Science and Technology (IUST), Tehran, Iran, in 1979, and his M.S. and Ph.D. in Power Electronics from Bradford University, West Yorkshire, U.K., in 1987 and 1990, respectively. He is a member of the faculty at IUST where he is currently an Associate Professor. His current research interests include microprocessor and microcontroller-based system designs, motor drives and control, HVDC transmissions, modulation strategies for power electronic systems, multilevel inverters, and power devices. Dr. Rahmati is a member of the Institution of Engineering and Technology (IET), U.K., and the Engineering Council, U.K.

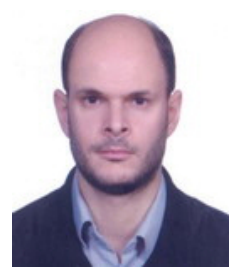

Shahriyar Kaboli received his B.S., M.S., and Ph.D. in Electrical Engineering from the Sharif University of Technology, Tehran, Iran, in 1997, 1999, and 2006, respectively. $\mathrm{He}$ is a member of the faculty at the Sharif University of Technology where he is currently an Assistant Professor. From 2003 to 2004, he spent a sabbatical period as a postdoctoral candidate at the Institute National Polytechnique de Grenoble, Grenoble, France. He has published more than 40 papers and technical reports in the field of Electrical Engineering. His current research interests include power electronics and electrical machines. Dr. Kaboli is a Reviewer for the IEEE Power Electronics Society and the IEEE Industrial Electronics Society. He received an Exceptional Talents Award from the Sharif University of Technology, in 2003, and a Financial Support Award from the Power Electronics and Motion Control Conference (EPEPEMC), in 2004. 